\title{
Physicians' knowledge and practice towards medical error reporting: a cross-sectional hospital-based study in Saudi Arabia
}

\author{
E. Alsafi, ${ }^{\prime}$ S. Baharoon, ${ }^{2}$ A. Ahmed, ${ }^{2}$ H.H. Al-Jahdali, ${ }^{2}$ S. Al Zahrani ${ }^{3}$ and A. Al Sayyari ${ }^{2}$
}

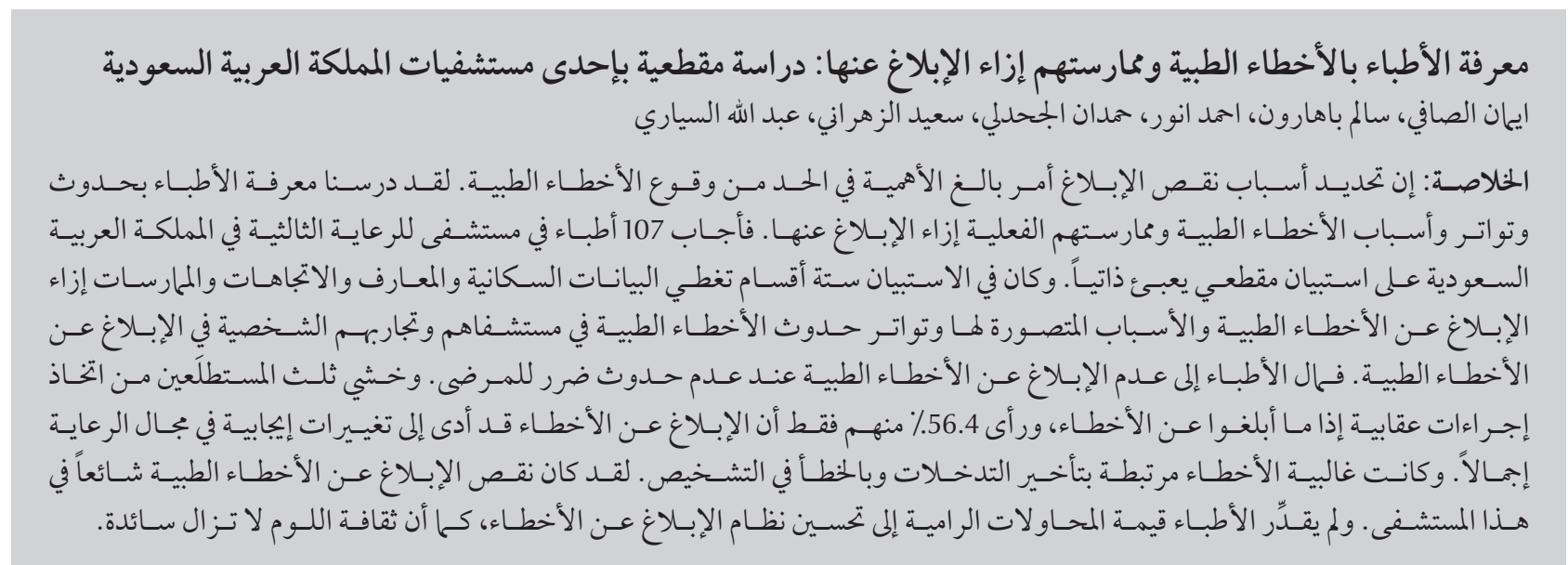

ABSTRACT Identifying reasons for under-reporting is crucial in reducing the incidence of medical errors. We studied physicians' knowledge of the occurrence, frequency and causes of medical errors and their actual practice toward reporting them. A cross-sectional, self-administered questionnaire was answered by 107 physicians at a tertiary-care hospital in Saudi Arabia. The questionnaire had 6 sections covering demographic data, knowledge, attitudes and practice towards reporting medical errors, perceived causes of and frequency of medical errors in their hospital and personal experiences of medical error reporting. Physicians tended not to report medical errors when no harm had occurred to patients. One-third of respondents feared punitive actions if they reported errors and only $56.4 \%$ felt that error reporting had led to positive changes in overall care. A majority of errors were related to late interventions and misdiagnosis. Under-reporting of medical errors was common in this hospital. Physicians did not appreciate attempts to improve the system of error reporting and a culture of blame still prevailed.

Connaissances et pratiques des médecins concernant la notification des erreurs médicales : étude transversale en milieu hospitalier en Arabie saoudite

RÉSUMÉ L'identification des raisons de la sous-notification est cruciale pour réduire l'incidence des erreurs médicales. Nous avons étudié les connaissances des médecins sur la survenue, la fréquence et les causes des erreurs médicales ainsi que leur pratique réelle en termes de notification. Un autoquestionnaire transversal a été rempli par 107 médecins dans un hôpital de soins tertiaires en Arabie saoudite. Le questionnaire présentait six sections couvrant les données démographiques, les connaissances, les attitudes et les pratiques vis-à-vis de la notification des erreurs médicales, les causes perçues et la fréquence des erreurs médicales dans leur hôpital ainsi que les expériences personnelles en matière de notification. Les médecins avaient tendance à ne pas notifier les erreurs médicales lorsque les patients n'avaient souffert d'aucun dommage. Un tiers des répondants craignaient les actions punitives s'ils notifiaient des erreurs et seuls 56,4 \% pensaient que la notification des erreurs entraînait des modifications positives pour l'ensemble des soins. Une majorité d'erreurs était liée à des interventions tardives et des erreurs de diagnostic. La sous-notification des erreurs médicales était fréquente dans cet hôpital. Les médecins ne percevaient pas positivement les tentatives d'amélioration du système de notification des erreurs et la culture du blâme restait prévalente. 


\section{Introduction}

Health-care providers' knowledge, attitude and practice towards medical errors and error reporting are essential factors to understand in order to reach a more transparent, better quality and safer health environment. Achieving a safer health-care environment will lead to reductions in the incidence of medical errors and adverse events. Encouraging medical error reporting with the aim of using the error as an educational exercise and quality improvement tool is an essential component in providing safety of care to patients (1). It is important that health-care providers appreciate that error reporting is truly an opportunity to improve care and a tool to ensure a safer environment. Although it is frequently emphasized that medical errors should not be seen as solely the result of an individual's mistake but rather of underlying defects in the health-care system, health-care providers may not see this being practised in reality (2).

There has been a recent increase in the frequency of medical error claims in Saudi Arabia (3). Nearly 40000 medical error complaints are filed annually, a third of medical practitioners are banned from travel due to those complaints and $80 \%$ of those complaints end without a conviction $(4,5)$. The frequency of such claims varies between provinces, but surgery and obstetric practice claims are the most frequent $(6,7)$. Despite the increase in claims, there is a belief that medical errors are still largely underreported by physicians $(8,9)$. While a need for more transparency in revealing these errors is evident, efforts to understand the reasons behind this increase are not well studied and tend to emphasize the frequency of occurrence of errors without getting health-care workers' perspectives $(6,7,10,11)$.

Saudi Arabian health-care providers have positive knowledge and attitudes toward patient safety $(12,13)$. Saudi physicians consider reporting medical errors as an ethical issue (9). Reinforcement of error reporting, implementing strict guidelines, training personnel efficiently and using the experience of professionals in appropriate fields will all enhance reporting and ultimately lead to improved care (9).

We have previously reported on the attitude of physicians toward reporting medical errors in a sample of health-care providers in Saudi Arabia and determined that physicians are likely to disclose errors made by a colleague only if the error resulted in severe damage to the patient; thus, many medical errors go under-reported (14). It was believed that the assurance of confidentiality and protection from repercussions would increase medical error disclosure (14). In the current article, we present the results of physicians' knowledge about the occurrence, frequency and causes of medical errors and their personal practice of medical error reporting.

\section{Methods}

\section{Study design and setting}

This cross-sectional study from 15-30 June 2011 used a self-administered survey questionnaire to doctors in a tertiary care Ministry of Health hospital in Riyadh, the capital city of Saudi Arabia. Al-Iman General Hospital is a 400-bed hospital located in the south of the city. It offers all subspecialties and accepts medical, surgical, trauma and obstetrics and gynaecology patients.

\section{Sampling}

The target population was all physicians working at Al-Iman General Hospital. The study coordinator distributed the study questionnaires to physicians in all clinical departments when they were attending their morning rounds and also during individual departments' academic activities and hospital-wide activities. We included all licensed physicians who were working full-time in the hospital for at least 1 year prior to enrolment in the study.

The purpose of the study was explained to participants and return of a filled questionnaire was considered consent to participate in the study. Completion of the questionnaire was not obligatory at the time of distribution and the participants were requested to return the completed and sealed questionnaires to departmental secretaries to be collected later by the study coordinators. The participants were assured that they would have both anonymity and confidentiality. The approval of the local institutional review board was obtained prior to commencing the study.

\section{Data collection}

The questionnaire used in this study was developed and previously validated by the study group (14). It was divided into 6 sections. Section 1 collected information about respondents' demographic and practice characteristics. Section 2 (attitude questions) asked the respondent about their incentives and barriers to medical error reporting. Section 3 (practice questions) examined the impact on medical error reporting of organizational culture, leadership and approaches to and procedures for handling medical error reporting and its consequences. Sections 4 (knowledge questions) collected information about the occurrence of medical errors in the hospital. Section 5 asked about the frequency with which medical errors were reported in the hospital. Section 6 enquired about specific and personal experiences of the respondents concerning medical error reporting. Sections 2, 3 and 4 of the survey asked the respondent to state his or her level of agreement with statements using a 3-point Likert scale from 1 (disagree) to 3 (agree).

\section{Statistical analyses}

The data were entered into the SPSS program, version 19 , which was also used for data management and analyses. Due to the descriptive nature of 
this study, the results were reported as both a number and percentage for categorical variables and the mean and standard deviation (SD) for continuous variables. The data from the Likert scales were presented as categorical variables (agreement or disagreement with the statement made).

\section{Results}

\section{Demographic and practice characteristics}

Of the 161 physicians invited to participate in this study, 107 (66.5\%) responded. Respondents were between 25-59 years old with a mean age of 39.8 (SD 9.0) years. Table 1 displays the demographic and practice data of the doctors who agreed to participate. The mean duration of their training was 11.6 (SD 9.8) years, and 67.3\% were males. Most were either residents or specialists (39.8\% and $30.1 \%$ respectively) and from the departments of emergency medicine and surgery $(19.6 \%$ and $17.7 \%$ respectively). Almost half of the respondents worked between 40-59 hours per week, while $17.1 \%$ worked 60-79 hours/week. Two-thirds of physicians $(66.0 \%)$ had $1-5$ years' experience in their current work and 20.0\% had more than 15 years' experience (Table 1).

\section{Practice of medical error reporting}

A total of 17 questions were asked about practices concerning medical error reporting in their hospital (Table 2 ). About $40 \%$ of physicians did not agree that there was fair treatment of staff physicians reporting medical errors. One-third of surveyed physicians (33.6\%) could not confirm that their roles and responsibilities in responding to medical errors and other safetyrelated issues were clearly laid out in their job description. Physicians conditioned their response to medical errors according to the likely harm done to the

\begin{tabular}{|c|c|c|}
\hline Parameter & No. & $\%$ \\
\hline \multicolumn{3}{|l|}{ Sex } \\
\hline Male & 72 & 67.3 \\
\hline Female & 35 & 32.7 \\
\hline \multicolumn{3}{|l|}{ Current position } \\
\hline General practitioner & 13 & 12.6 \\
\hline Specialist & 31 & 30.1 \\
\hline Resident & 41 & 39.8 \\
\hline Consultant & 18 & 17.5 \\
\hline \multicolumn{3}{|l|}{ Nationality } \\
\hline Saudi Arabian & 15 & 14.0 \\
\hline Expatriate & 92 & 86.0 \\
\hline \multicolumn{3}{|l|}{ Location of specialty training } \\
\hline Middle East & 65 & 67.0 \\
\hline Asia & 3 & 3.1 \\
\hline Europe & 15 & 15.5 \\
\hline North America & 5 & 5.2 \\
\hline Other & 9 & 9.3 \\
\hline \multicolumn{3}{|l|}{ Department } \\
\hline Dental & 3 & 2.8 \\
\hline Emergency medicine & 21 & 19.6 \\
\hline Clinical laboratory & 4 & 3.7 \\
\hline Medicine & 18 & 16.8 \\
\hline Obstetrics and gynaecology & 16 & 15.0 \\
\hline Paediatrics & 9 & 8.4 \\
\hline Surgery & 18 & 17.7 \\
\hline Other & 18 & 16.0 \\
\hline \multicolumn{3}{|l|}{ Working hours/week } \\
\hline 20-39 & 35 & 33.3 \\
\hline $40-59$ & 52 & 49.5 \\
\hline $60-79$ & 18 & 17.1 \\
\hline \multicolumn{3}{|c|}{ Work experience in specialty (years) } \\
\hline$<1$ & 6 & 10.0 \\
\hline$\geq 16$ & 9 & 15.0 \\
\hline $1-5$ & 33 & 66.0 \\
\hline 11-15 & 12 & 20.0 \\
\hline
\end{tabular}

patient; $49.0 \%$ would not report an error if no harm were inflicted, although $42.0 \%$ would report it anyway. Only 30.5\% of physicians agreed that hospital management did not blame them after reporting errors and only $56.4 \%$ felt that reporting medical errors would lead to positive changes anyway (Table 2).

Two-thirds of surveyed physicians affirmed a positive role of the hospital chairman and directors in providing adequate support when problems arose and in encouraging the staff to find positive solutions for these problems, but only $50.0 \%$ said that they were given feedback about changes put into place based on event and errors reported (Table 2). Many of the physicians ( $42.4 \%$ ) could not affirm having effective mechanisms for reporting medical errors and another $27.6 \%$ were unsure or disagreed that the hospital had policies and procedures that 


\begin{tabular}{|c|c|c|c|}
\hline Statement & Agree & Don't know & Don't agree \\
\hline $\begin{array}{l}\text { The practice in this hospital allow for a fair treatment when reporting } \\
\text { medical errors }\end{array}$ & 60.8 & 13.7 & 25.5 \\
\hline I do not report the error if I think the patient is not harmed & 49.0 & 8.8 & 42.2 \\
\hline $\begin{array}{l}\text { I try to report a medical error because reporting might prevent further } \\
\text { complications to the patient }\end{array}$ & 84.6 & 2.8 & 12.6 \\
\hline $\begin{array}{l}\text { I feel comfortable to ask for help or support from my colleagues or peers } \\
\text { concerning medical errors }\end{array}$ & 69.9 & 11.7 & 18.4 \\
\hline $\begin{array}{l}\text { I have the opportunity to discuss and receive feedback about my work } \\
\text { performance with other staff }\end{array}$ & 77.0 & 14.0 & 9.0 \\
\hline $\begin{array}{l}\text { The system in my hospital including policy and procedure is good at } \\
\text { minimizing occurrence of medical errors }\end{array}$ & 72.4 & 12.4 & 15.2 \\
\hline $\begin{array}{l}\text { Expectations of medical staff in my workplace subject them to constant } \\
\text { pressure that increases chances of errors }\end{array}$ & 23.1 & 20.2 & 56.7 \\
\hline $\begin{array}{l}\text { Medical staff feel like their mistakes are held against them when an event is } \\
\text { reported }\end{array}$ & 30.5 & 14.3 & 55.2 \\
\hline Reporting medical errors has led to positive changes & 56.4 & 19.8 & 23.8 \\
\hline Chairman and directors provide adequate support when problems arise & 67.9 & 15.1 & 17.0 \\
\hline $\begin{array}{l}\text { Chairman and directors encourage staff to find positive solutions when } \\
\text { problems arise }\end{array}$ & 68.9 & 20.8 & 10.3 \\
\hline $\begin{array}{l}\text { We are given feedback about changes put into place based on event and } \\
\text { errors reported }\end{array}$ & 50.0 & 25.0 & 25.0 \\
\hline We have effective mechanisms of reporting medical errors & 57.6 & 21.7 & 20.7 \\
\hline $\begin{array}{l}\text { When it comes to reporting medical errors, things are quite disorganized } \\
\text { in my workplace }\end{array}$ & 25.2 & 29.1 & 45.7 \\
\hline $\begin{array}{l}\text { Staff roles and responsibilities in responding to medical errors and other } \\
\text { safety related issues are clearly laid out in their job descriptions }\end{array}$ & 66.4 & 15.8 & 17.8 \\
\hline $\begin{array}{l}\text { This hospital promotes itself as an organization that responds to medical } \\
\text { errors and other safety-related issues }\end{array}$ & 53.8 & 25.0 & 21.2 \\
\hline This hospital is receptive to staff ideas and suggestions regarding medical errors & 47.6 & 25.2 & 27.2 \\
\hline
\end{tabular}

were effective for minimizing the occurrence of medical errors.

Only 53.8\% of respondents agreed that their hospital promoted itself as an organization that responded to medical errors and other safety-related issues and less than half $(47.6 \%)$ considered that the hospital was receptive to the staffs ideas and suggestions regarding medical errors and other safety-related issues.

\section{Knowledge of medical error reporting}

There were 15 statements in the category of knowledge about medical error reporting (Table 3 ). The majority of respondents thought that there was under-reporting of medical errors in the hospital and that staff shortages and overload, lack of experience and training and poor language and communication were all important causes of medical errors in the hospital. Respondents disagreed that the medical administration dealt with medical errors confidentially (58.1\%), and 51.0\% could not clearly say that the administration had a positive impact in promoting disclosure of errors. Around half of respondents (51.0\%) disagreed that the reason for not disclosing errors was because the reporting process was unclear, although 64.8\% did not concur that reporting errors was simple and not time-consuming.

The final statement referred to the respondents' opinion about the medical fields in which errors were most frequently encountered. In all areas (medication, diagnostic, surgical, transfusion, laboratory, late interventions), respondents felt that errors were most frequently related to late interventions followed by laboratory and diagnosis medical errors. Surgery-related medical errors were less mentioned, followed by medication-related errors. Transfusionrelated errors were the lowest in occurrence according to respondents.

\section{Physicians' characteristics and medical error reporting}

Table 4 shows the mean scores of physicians on practice and knowledge of medical error reporting in relation to their demographic and practice characteristics. Physicians who worked long hours (60-79 hours) had poorer 


\begin{tabular}{|c|c|c|c|}
\hline Statement & Agree & Don't know & Don't agree \\
\hline I think there is under-reporting of medical errors in the hospital & 50.0 & 28.8 & 21.2 \\
\hline $\begin{array}{l}\text { I think shortage and overload is one cause of medical error occurrence in the } \\
\text { hospital }\end{array}$ & 74.0 & 12.5 & 13.5 \\
\hline I think lack of experience and training is one cause of medical errors & 81.9 & 9.5 & 8.6 \\
\hline $\begin{array}{l}\text { I think poor language and communication could be one significant cause of } \\
\text { medical errors }\end{array}$ & 70.8 & 10.7 & 18.5 \\
\hline $\begin{array}{l}\text { The medical administration office has a positive contribution in promoting error } \\
\text { reporting }\end{array}$ & 49.0 & 39.2 & 11.8 \\
\hline $\begin{array}{l}\text { The medical administration office deals confidentially with medical errors that are } \\
\text { reported }\end{array}$ & 19.0 & 22.9 & 58.1 \\
\hline $\begin{array}{l}\text { To my knowledge the cause of not reporting medical errors is that the reporting } \\
\text { process is not clear }\end{array}$ & 49.0 & 21.2 & 29.8 \\
\hline $\begin{array}{l}\text { To my knowledge the cause of not reporting medical errors is the reporting } \\
\text { process is complex and time consuming }\end{array}$ & 35.2 & 23.8 & 41.0 \\
\hline $\begin{array}{l}\text { In my opinion, the most frequently encountered medical errors in this hospital } \\
\text { are medication related }\end{array}$ & 35.9 & 37.9 & 26.2 \\
\hline $\begin{array}{l}\text { In my opinion, the most frequently encountered medical errors in this hospital } \\
\text { are patient falls }\end{array}$ & 38.1 & 34.3 & 27.6 \\
\hline $\begin{array}{l}\text { In my opinion, the most common medical errors in this hospital are diagnostic } \\
\text { related }\end{array}$ & 45.7 & 41.9 & 12.4 \\
\hline $\begin{array}{l}\text { In my opinion, the most frequently encountered medical errors in this hospital } \\
\text { are related to late interventions }\end{array}$ & 47.1 & 36.3 & 16.6 \\
\hline $\begin{array}{l}\text { In my opinion, laboratory related medical errors are the most frequently } \\
\text { encountered in my hospital }\end{array}$ & 46.7 & 37.0 & 16.3 \\
\hline $\begin{array}{l}\text { In my opinion, transfusion related medical errors are the most frequently } \\
\text { encountered in my hospital }\end{array}$ & 28.6 & 36.2 & 35.2 \\
\hline $\begin{array}{l}\text { In my opinion, surgical related medical errors are the most frequently } \\
\text { encountered in my hospital }\end{array}$ & 40.9 & 34.3 & 24.8 \\
\hline
\end{tabular}

practice scores for reporting errors compared with physicians who worked fewer hours $(P=0.046)$. Physicians in obstetrics departments had better self-reported practice (i.e. lower scores) for reporting medical errors than did other specialities, although the numbers were not statistical ly significant $(P=0.063)$ (Table 4).

There were no significant effects of sex, age, position, specialty, department or year of specialty on physicians' knowledge scores although non-Saudi physician had a better knowledge score $(P=0.054)$ (Table 4).

The practice questions in Section 3 examined the impact on medical error reporting of organizational culture, leadership and approaches to and procedures for handling medical error reporting and its consequences Three questions were asked about the conditions for reporting medical errors (Table 5): those discovered before they affect the patient, those that occur but do not harm the patient and those that occur and cause harm. Compared with male doctors, more female physicians felt that disclosure of errors was dependent on the potential harm caused $(P=0.03)$.

\section{Frequency of reporting errors}

When asked how frequently they had filed medical error reports in the past year, $61 \%$ of the physicians said they had not filed an error in the previous 12 months, $21 \%$ had filed 1 or 2 error reports, $8 \%$ had filed $3-5$ reports, $7 \%$ had filed 6-10 error reports and one respondent had filed more than 20 medical errors reports. Physicians working between 20-39 hours were statistically more likely to report fewer errors compared with those who worked more hours (Figure 1). The overall self-reporting of errors across all residents, specialists, consultants and general practitioners were low. There were higher reporting trends among residents compared with other groups.

Errors were most likely to reported by obstetric physicians (38.9\%) and the least likely by surgical physicians (18.2\%) $(P=0.019)$ (Table 6).

\section{Discussion}

Transparency plays a major role in the overall success of most organizations and hospitals and the medical 


\begin{tabular}{|c|c|c|c|c|c|c|}
\hline \multirow[t]{2}{*}{ Characteristic } & \multicolumn{3}{|c|}{ Practice scores } & \multicolumn{3}{|c|}{ Knowledge scores } \\
\hline & Mean & (SD) & $P$-value ${ }^{a}$ & Mean & (SD) & $P$-value ${ }^{a}$ \\
\hline \multicolumn{7}{|l|}{ Sex } \\
\hline Male & 2.34 & $(0.27)$ & \multirow[t]{2}{*}{0.098} & 2.38 & $(0.36)$ & \multirow[t]{2}{*}{0.917} \\
\hline Female & 2.25 & $(0.25)$ & & 2.38 & $(0.42)$ & \\
\hline \multicolumn{7}{|l|}{ Age (years) } \\
\hline$<35$ & 2.30 & $(0.27)$ & \multirow[t]{3}{*}{0.956} & 2.40 & $(0.37)$ & \multirow[t]{3}{*}{0.820} \\
\hline $35-45$ & 2.32 & $(0.27)$ & & 2.36 & $(0.37)$ & \\
\hline$>45$ & 2.32 & $(0.25)$ & & 2.42 & $(0.44)$ & \\
\hline \multicolumn{7}{|l|}{ Nationality } \\
\hline Expatriate & 2.30 & $(0.27)$ & \multirow[t]{2}{*}{0.311} & 2.36 & $(0.39)$ & \multirow[t]{2}{*}{0.054} \\
\hline Saudi Arabian & 2.39 & $(0.22)$ & & 2.55 & $(0.23)$ & \\
\hline \multicolumn{7}{|l|}{ Current position } \\
\hline Consultant & 2.34 & $(0.26)$ & \multirow[t]{4}{*}{0.895} & 2.42 & $(0.31)$ & \multirow[t]{4}{*}{0.788} \\
\hline Specialist & 2.32 & $(0.28)$ & & 2.42 & $(0.39)$ & \\
\hline Resident & 2.29 & $(0.26)$ & & 2.33 & $(0.41)$ & \\
\hline General practitioner & 2.31 & $(0.27)$ & & 2.43 & $(0.33)$ & \\
\hline \multicolumn{7}{|c|}{ Location of specialty training } \\
\hline Middle East & 2.32 & $(0.28)$ & \multirow[t]{3}{*}{0.431} & 2.38 & $(0.37)$ & \multirow[t]{3}{*}{0.212} \\
\hline Europe/North America & 2.25 & $(0.24)$ & & 2.29 & $(0.40)$ & \\
\hline Other & 2.34 & $(0.24)$ & & 2.49 & $(0.37)$ & \\
\hline \multicolumn{7}{|l|}{ Primary work area (field) } \\
\hline Medicine & 2.26 & $(0.27)$ & \multirow[t]{5}{*}{0.063} & 2.46 & $(0.38)$ & \multirow[t]{5}{*}{0.429} \\
\hline Surgery & 2.25 & $(0.29)$ & & 2.33 & $(0.37)$ & \\
\hline Emergency medicine & 2.44 & $(0.23)$ & & 2.47 & $(0.32)$ & \\
\hline Obstetrics & 2.24 & $(0.22)$ & & 2.24 & $(0.54)$ & \\
\hline Other & 2.35 & $(0.25)$ & & 2.39 & $(0.22)$ & \\
\hline \multicolumn{7}{|l|}{ Working hours/week } \\
\hline 20-39 & 2.26 & $(0.26)$ & \multirow[t]{3}{*}{0.046} & 2.40 & $(0.34)$ & \multirow[t]{3}{*}{0.347} \\
\hline $40-59$ & 2.38 & $(0.24)$ & & 2.40 & $(0.41)$ & \\
\hline $60-79$ & 2.22 & $(0.30)$ & & 2.29 & $(0.38)$ & \\
\hline \multicolumn{7}{|c|}{ Work experience in specialty (years) } \\
\hline$\leq 5$ & 2.28 & $(0.28)$ & \multirow[t]{3}{*}{0.493} & 2.38 & $(0.42)$ & 0.301 \\
\hline $6-15$ & 2.35 & $(0.22)$ & & 2.35 & $(0.36)$ & \\
\hline$>15$ & 2.27 & $(0.33)$ & & 2.51 & $(0.30)$ & \\
\hline No. of adverse events repo & & & & & & \\
\hline 0 & 2.30 & $(0.26)$ & 0.121 & 2.33 & $(0.41)$ & 0.064 \\
\hline $1-2$ & 2.40 & $(0.22)$ & & 2.53 & $(0.30)$ & \\
\hline$\geq 3$ & 2.22 & $(0.30)$ & & 2.42 & $(0.27)$ & \\
\hline
\end{tabular}

${ }^{a}$ Kruskal-Wallis/Mann-Whitney U-test.

$S D=$ standard deviation .

community is no exception. Therefore, the disclosure of medical errors is one major form of transparency that can dictate the overall efficiency of the existing health-care system. Physicians' knowledge that medical errors are under-reported in their hospital was evident in the present survey in Saudi Arabia. Under-reporting of medical errors by physicians has many causes. Reluctance to report violations may be a function of the widespread and well-documented resistance among doctors to adhere to clinical protocols, which are perceived by many in the medical community as a threat to their professional autonomy $(15,16)$. This resistance to adherence was reported 


\begin{tabular}{|c|c|c|c|c|c|c|c|c|c|c|c|c|}
\hline \multirow{3}{*}{$\begin{array}{l}\text { Physicians who would disclose } \\
\text { medical error if the error: }\end{array}$} & \multicolumn{3}{|c|}{ Sometimes } & \multicolumn{3}{|c|}{ Always } & \multicolumn{3}{|c|}{ Most of the time } & \multicolumn{3}{|c|}{ Rarely } \\
\hline & $\mathbf{M}$ & $\mathbf{F}$ & Total & $\mathbf{M}$ & $\mathbf{F}$ & Total & $\mathbf{M}$ & $\mathbf{F}$ & Total & $\mathbf{M}$ & $\mathbf{F}$ & Total \\
\hline & $\%$ & $\%$ & $\%$ & $\%$ & $\%$ & $\%$ & $\%$ & $\%$ & $\%$ & $\%$ & $\%$ & $\%$ \\
\hline $\begin{array}{l}\text { Were corrected before it affected the } \\
\text { patient }\end{array}$ & 42 & 34 & 38.5 & 8 & 15 & 10.6 & 21 & 30 & 24.0 & 29 & 21 & 26.9 \\
\hline Did not harm the patient & 31 & 36 & 32.7 & 4 & 19 & 8.7 & 33 & 13 & 26.9 & 31 & 33 & 31.7 \\
\hline Harmed the patient & 15 & 28 & 19.4 & 29 & 49 & 35.0 & 30 & 10 & 21.8 & 18 & 15 & 8.7 \\
\hline
\end{tabular}

$M=$ males $;=$ females.

by another survey among health-care providers in Saudi Arabia (17). Physicians' willingness to report errors to the hospital, as well as to discuss errors with tarnishing their professional reputation colleagues and patients, may be dimin- among colleagues and patients $(15,18)$. ished by fear of litigation and concern of Although one may speculate that being
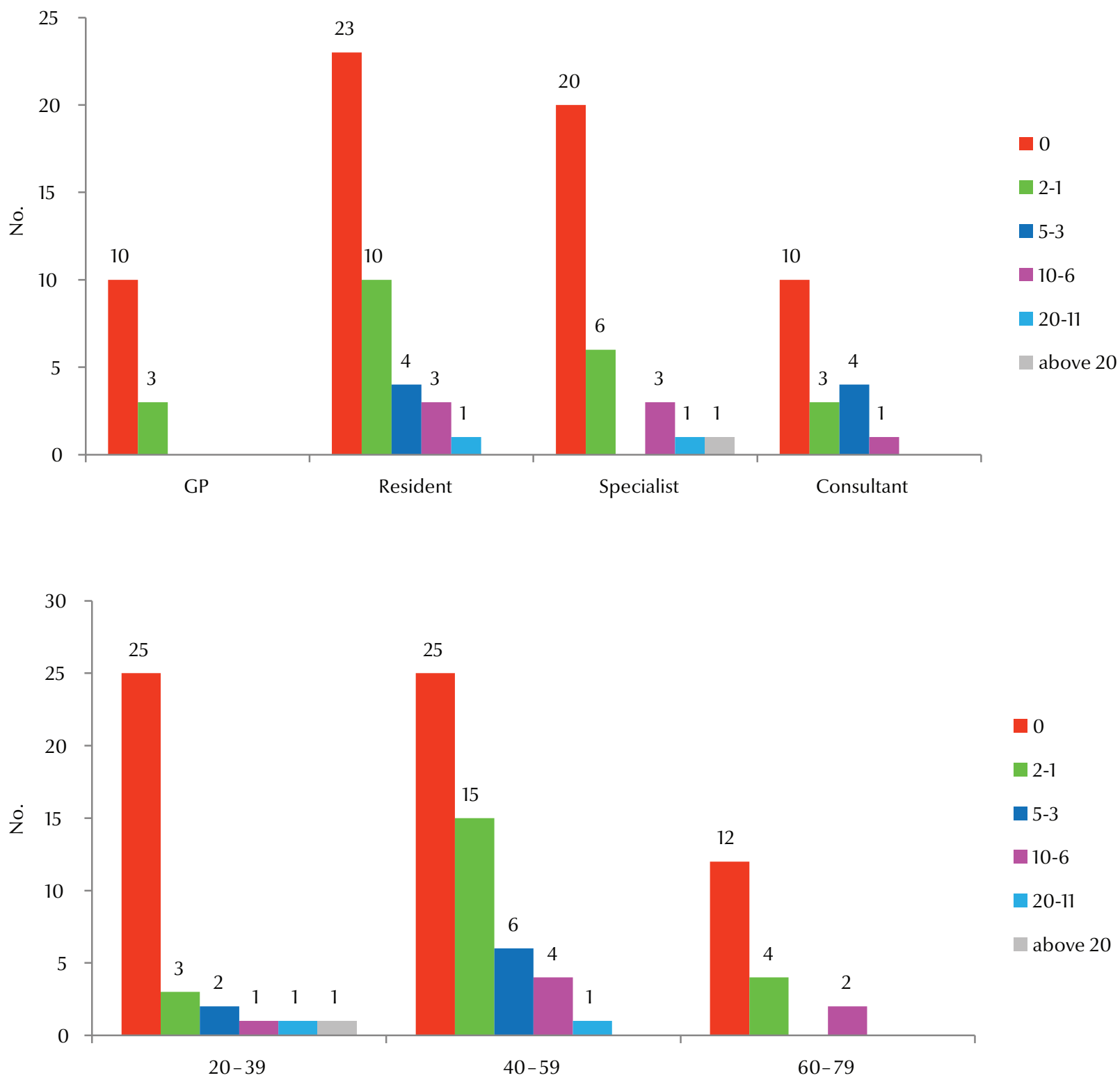

Figure 1 Cross-tabulation between physicians' reporting of medical errors and (a) work hours/week and (b) specialty training 


\begin{tabular}{|c|c|c|c|c|c|}
\hline \multirow[t]{3}{*}{ Characteristic } & \multicolumn{4}{|c|}{ Errors reported } & \multirow[b]{3}{*}{$P$-value ${ }^{\text {a }}$} \\
\hline & \multicolumn{2}{|c|}{ No } & \multicolumn{2}{|c|}{ Yes } & \\
\hline & No. & $\%$ & No. & $\%$ & \\
\hline \multicolumn{6}{|l|}{ Sex } \\
\hline Male & 46 & 63.9 & 26 & 36.1 & \multirow[t]{2}{*}{0.696} \\
\hline Female & 21 & 60.0 & 14 & 40.0 & \\
\hline \multicolumn{6}{|l|}{ Age (years) } \\
\hline$<35$ & 27 & 62.8 & 16 & 37.2 & \multirow[t]{3}{*}{0.816} \\
\hline $35-45$ & 27 & 60.0 & 18 & 40.0 & \\
\hline$>45$ & 13 & 68.4 & 6 & 31.6 & \\
\hline \multicolumn{6}{|l|}{ Nationality } \\
\hline Expatriate & 58 & 63.0 & 34 & 37.0 & \multirow[t]{2}{*}{0.821} \\
\hline Saudi Arabian & 9 & 60.0 & 6 & 40.0 & \\
\hline \multicolumn{6}{|l|}{ Position } \\
\hline Consultant & 10 & 55.6 & 8 & 44.4 & \multirow[t]{4}{*}{0.451} \\
\hline Specialist & 17 & 54.8 & 14 & 45.2 & \\
\hline Resident & 30 & 66.7 & 15 & 33.3 & \\
\hline General practitioner & 10 & 76.9 & 3 & 23.1 & \\
\hline \multicolumn{6}{|c|}{ Location of specialty training } \\
\hline Middle East & 42 & 60.0 & 28 & 40.0 & \multirow[t]{3}{*}{0.544} \\
\hline Europe/North America & 11 & 61.1 & 7 & 38.9 & \\
\hline Other & 14 & 73.7 & 5 & 26.3 & \\
\hline \multicolumn{6}{|l|}{ Primary work area (field) } \\
\hline Medicine & 16 & 64.0 & 9 & 36.0 & \multirow[t]{5}{*}{0.019} \\
\hline Surgery & 18 & 81.8 & 4 & 18.2 & \\
\hline Emergency medicine & 16 & 69.6 & 7 & 30.4 & \\
\hline Obstetrics & 11 & 61.1 & 7 & 38.9 & \\
\hline Other & 6 & 31.6 & 13 & 68.4 & \\
\hline \multicolumn{6}{|l|}{ Working hours/week } \\
\hline 20-39 & 27 & 75.0 & 9 & 25.0 & \multirow[t]{3}{*}{0.098} \\
\hline $40-59$ & 28 & 52.8 & 25 & 47.2 & \\
\hline $60-79$ & 12 & 66.7 & 6 & 33.3 & \\
\hline \multicolumn{6}{|l|}{ Years of specialty training } \\
\hline$\leq 5$ & 27 & 69.2 & 12 & 30.8 & \multirow[t]{3}{*}{0.288} \\
\hline $6-15$ & 32 & 62.7 & 19 & 37.3 & \\
\hline$>15$ & 8 & 47.1 & 9 & 52.9 & \\
\hline
\end{tabular}

${ }^{a}$ Chi-squared test.

an expatriate working in Saudi Arabia may be another major contribution to low reporting, due to fear of losing one's reputation or job and/or fear of punishment, the results of our study did not confirm this. Both Saudi nationals and expatriates reported having similar medical error reporting practices, although expatriates tended to have a better knowledge score.
In our study physicians acknowledged that incompetence or lack of sufficient training and background led to medical errors. It is apparent that one has to be equipped with a certain level of expertise and a degree of professionalism to keep medical errors to a minimum. Furthermore, it is important for the medical profession to take measures at both an individual and organizational level to avoid medical errors $(15,18)$.

One factor that was apparent from this survey was that most doctors did not think it was necessary to disclose an error if it did not severely harm the patient. It is commonly accepted among the majority of doctors that errors are an "inevitable" and potentially unmanageable feature of medical work and that incident reporting 
is therefore "pointless" (19). This belief, however, does not supersede the importance of disclosing errors, especially if the consequences are patient death.

Most of our respondents did not think that the hospital administration implemented protocols to promote confidentiality and fairness in the disclosure of errors. One way to address this issue is to openly share experiences in a confidential setting which effectively helps diffuse feelings of guilt and which challenges the culture of shame and isolation that often surrounds medical errors (19). Furthermore, as discussed by Hebert et al., disclosures should be made easier and not riskier for health-care practitioners so that clinicians can learn from mistakes and improve patient care (20).

Al-Iman General Hospital is first and foremost a government hospital and, as such, the hospital's protocols are established by the Saudi Ministry of Health, which does not have concrete protocols for error disclosure. Similarly, in Canada, error disclosure is not explicitly addressed in the new Canadian Medical Association's Code of Ethics. In addition, most professional bodies, such as the College of Physicians and Surgeons of Ontario, the Province's regulatory body for physicians, have no policies requiring physicians to disclose errors except in some circumstances of professional incompetence or incapacity (20). In the United States, however, the Joint Commission on Accreditation of Health Care Organizations requires hospitals to inform patients of care outcomes, including anticipated outcomes and disclosure (21). The Ministry of Health of Saudi Arabia should adopt a similar programme - one which is both patientand physician-friendly with regards to transparency - and implement the programme throughout all the hospitals in the country. In the current study the lack of existing unified protocols was evident. For example, $49.0 \%$ of responders stated that the reporting process was not clear while only $41.0 \%$ thought that the process was simple and not time consuming.
System barriers are factors that are inherent in the system that may hinder addressing medical errors. In the emergency department, these have been shown to include high patient volumes, multiple transitions during care and lack of followup care. These cases usually inhibit the physician's ability to disclose errors because the transfer of information is often deficient in detail, imprecise, delayed and badly organized. The lack of follow-up care also hinders error disclosure in the sense that it does not provide an opportunity to determine, report or investigate an error (21). Surgeons and emergency physicians were the least likely to report medical errors in the current study.

In this study, those who were working the greatest number of hours tended to report fewer errors; this finding confirms that an increased workload diminishes the opportunity to report errors. Another form of system barrier is the lack of leadership in hospitals that promotes the value of error reporting or disclosure. Improvements in the system cannot happen if there is no leadership or support from the administration that addresses the importance of patient safety (22).

Physician barriers strongly affect error disclosure. The attitude and behaviour of physicians become barriers to reporting medical errors. When there is an incidence of medical error, physicians are more likely to feel a sense of failure. They may consequently develop feelings of shame, guilt and professional incompetence. Despite the fact that physicians recognize the importance of disclosing medical errors, they may be inhibited from doing so because they might not possess the training and proper communication skills to address this type of situation (23).

It has been demonstrated before that most physicians also fear the possibility of losing the trust of their patients. This fear causes further negative implications to the patients because the patients may tend to decrease cooperation to treatment plans, develop unwarranted worry about their treatment, and stop seeking professional health care in the future. While some believe that error disclosure wears away patients' trust, there are others who believe that it enhances trust because error disclosure promotes honesty and good communication between patients and physicians (23). In many hospitals, there is also a culture of blame when there is an error reported. The most common object of blame is the attending physician, although the underlying cause of error might be a system failure. This culture of blame must be transformed into a culture of patient safety to promote error reporting, regardless of whether the error causes an adverse event (1).

Physicians also encounter the risk of malpractice liability, and legal barriers may impede them from disclosing medical errors. When the error is not reported, patients will not be aware that an error was made. However, when an error is disclosed, the patient may take legal action to receive compensation for the harm they have suffered. Disclosure of errors by physicians, as well as their apology, could be used as evidence against them during a trial (23). Medical malpractice in Saudi Arabia is referred to the National MedicoLegal Committee where the cases are evaluated before being given a verdict $(20,21)$. Because most physicians are expatriates, the fear of deportation and the loss of the right to practice medicine could definitely impede the disclosure of medical errors. One suggestion from the Institute of Medicine in the United States regarding legal barriers is to encourage legislative action for peer-reviewed protection as well as for the protection of the reported information. As a result, the reporters of medical errors will be given adequate protection (24). This suggestion needs to be thoroughly studied in Saudi Arabia before it can be implemented to ensure that it adheres to Islamic principles and does not violate Sharia law. Alternatively, the recent study from Asqhari et al. on Iranian doctors suggested that the most 
acceptable approach to dealing with a peer's medical error is to report it to the responsible doctor and encourage him/ her to disclose it to the patient (22).

A weakness in our study was that the majority of our sample population (85.7\%) were expatriate, non-Saudi doctors. It is conceivable that this group may be more reluctant to report their own errors or the errors of their colleagues; therefore, the results cannot be generalized to all Saudi physicians. Nevertheless, this is still a useful study in the context of Saudi Arabia, where more than $80.7 \%$ of doctors working in the Ministry of Health are expatriates. Another weakness of our study was that we sampled from only one hospital, and thus the results may not be extrapolated to other hospitals.

\section{Conclusion}

In conclusion, this study is the first in Saudi Arabia to evaluate physicians' knowledge about the occurrence, frequency and causes of medical errors and their personal practice of medical error reporting. Under-reporting of medical errors was common in this hospital. Physicians did not appreciate attempts to improve the system of error reporting and a culture of blame still prevailed. The burden of promoting medical error reporting is on the physicians, health-care institutions and administrators. Health-care institutions should adopt a programme that enhances and promotes error reporting. This should entail transparency, confidentiality and a no-blame culture.

\section{Funding: None.}

Competing interests: None declared

\section{References}

1. McFadden KL, Stock GN, Gowen CR 3rd. Implementation of patient safety initiatives in US hospitals. Int J Oper Prod Manage. 2006;26(3):326-47

2. Kalra J. Medical errors: an introduction to concepts. Clin Biochem. 2004 Dec;37(12):1043-51. PMID:15589809

3. Shaheen AN. Medical errors in Saudi hospitals at alarming levels. Gulfnews Saudi Arabia. 2011 Jan 8;Sect. News (http:// gulfnews.com/news/gulf/saudi-arabia/medical-errors-insaudi-hospitals-at-alarming-levels-1.742903, accessed 20 August 2015).

4. Al-Harby N. Medical Errors Symposium [Internet] Alriyadh. 2007 Feb 18 (http://www.alriyadh.com/ 2007/02/18 /article225849.html, accessed 20 August 2015).

5. Samarkandi A. Status of medical liability claims in Saudi Arabia. Ann Saudi Med. 2006 Mar-Apr;26(2):87-91. PMID:16761443

6. Aljarallah JS, Alrowaiss N. The pattern of medical errors and litigation against doctors in Saudi Arabia. J Family Community Med. 2013 May;20(2):98-105. PMID:23983561

7. Henary BY, Al-Yahia OA, Al-Gabbany SA, Al-Kharaz SM. Epidemiology of medico-legal litigations and related medical errors in Central and Northern Saudi Arabia. A retrospective prevalence study. Saudi Med J. 2012 Jul;33(7):768-75. PMID:22821312

8. Alshaikh M, Mayet A, Aljadhey $\mathrm{H}$. Medication error reporting in a university teaching hospital in Saudi Arabia. J Patient Saf. 2013 Sep;9(3):145-9. PMID:23370218

9. Aldaqal SM, Al-Amoodi MS. To report or not: the dilemma of reporting medical errors among physicians. Adv Bioscience Clin Med. 2014 Jan;2(2):49-57.

10. Tobaiqy M, Stewart D. Exploring health professionals' experiences of medication errors in Saudi Arabia. Int J Clin Pharm. 2013 Aug;35(4):542-5. PMID:23649894

11. Arabi Y, Alamry A, Al Owais SM, Al-Dorzi H, Noushad S, Taher S. Incident reporting at a tertiary care hospital in Saudi Arabia. J Patient Saf. 2012 Jun;8(2):81-7. PMID:22525364

12. Al-Khaldi YM. Attitude of primary care physicians toward patient safety in Aseer region, Saudi Arabia. J Family Community Med. 2013 Sep;20(3):153-8. PMID:24672271

13. Almaramhy H, Al-Shobaili H, El-Hadary K, Dandash K. Knowledge and attitude towards patient safety among a group of undergraduate medical students in saudi arabia. Int J Health Sci (Qassim). 2011 Jan;5(1):59-67. PMID:22489231

14. Alsafi E, Bahroon SA, Tamim H, Al-Jahdali HH, Alzahrani $\mathrm{S}$, Al Sayyari A. Physicians' attitudes toward reporting medical errors-an observational study at a general hospital in Saudi Arabia. J Patient Saf. 2011 Sep;7(3):144-7. PMID:21857239

15. Lawton R, Parker D. Barriers to incident reporting in a healthcare system. Qual Saf Health Care. 2002 Mar;11(1):15-8. PMID:12078362

16. Kingston MJ, Evans SM, Smith BJ, Berry JG. Attitudes of doctors and nurses towards incident reporting: a qualitative analysis. Med J Aust. 2004 Jul 5;181(1):36-9. PMID:15233611

17. Abudahish $\mathrm{A}$, Bella $\mathrm{H}$. Adherence of primary care physicians in Aseer region, Saudi Arabia to the National Protocol for the Management of Asthma. East Mediterr Health J. 2010 Feb;16(2):171-5. PMID:20799570

18. Garbutt J, Brownstein DR, Klein EJ, Waterman A, Krauss MJ, Marcuse EK, et al. Reporting and disclosing medical errors: pediatricians' attitudes and behaviors. Arch Pediatr Adolesc Med. 2007 Feb;161(2):179-85. PMID:17283304

19. Waring JJ. Beyond blame: cultural barriers to medical incident reporting. Soc Sci Med. 2005 May;60(9):1927-35. PMID:15743644

20. Hébert PC, Levin AV, Robertson G. Bioethics for clinicians: 23. Disclosure of medical error. CMAJ. 2001 Feb 20;164(4):50913. PMID:11233873

21. LeGros N, Pinkall JD; Joint Commission on Accreditation of Healthcare Organizations. The new JCAHO patient safety standards and the disclosure of unanticipated outcomes. J Health Law. 2002 Spring;35(2):189-210. PMID:12125881

22. Asghari F, Fotouhi A, Jafarian A. Doctors' views of attitudes towards peer medical error. Qual Saf Health Care. 2009 Jun;18(3):209-12. PMID:19468004

23. Penson RT, Svendsen SS, Chabner BA, Lynch TJ Jr, Levinson W. Medical mistakes: a workshop on personal perspectives. Oncologist. 2001;6(1):92-9. PMID:11161232

24. Moskop JC, Geiderman JM, Hobgood CD, Larkin GL. Emergency physicians and disclosure of medical errors. Ann Emerg Med. 2006 Nov:48(5):523-31. PMID:17052552 